Revistade
Economid
Contemporâned

\title{
DETERMINANTES MACROECONÔMICOS DOS INVESTIMENTOS NO BRASIL: UM ESTUDO PARA O PERÍODO 1996-2012
}

\author{
Marcos Tadeu Caputi Lélis ${ }^{a}$ \\ Sabrina Monique Schenato Bredow ${ }^{b}$ \\ André Moreira Cunha ${ }^{c}$ \\ aPrograma de Pós-Graduação em Economia da Unisinos. \\ ${ }^{\text {bC } C u r s o ~ d e ~ m e s t r a d o ~ e m ~ E c o n o m i a ~ d a ~ U n i s i n o s . ~}$ \\ 'Departamento de Economia e Relações Internacionais da Universidade Federal do Rio Grande do Sul \\ (UFRGS). Pesquisador do Conselho Nacional de Desenvolvimento Científico e Tecnológico (CNPq).
}

Artigo recebido em 24/10/2014 e aceito em 24/08/2015.

RESUMO: O presente trabalho discute os determinantes do investimento privado na economia brasileira no período 1996-2012. Mais especificamente, busca-se compreender quais variáveis macroeconômicas afetaram os gastos com bens de investimento no segmento de máquinas e equipamentos (FBME). Após decompor as séries utilizadas nos seus componentes não observados e aplicar um modelo vetorial de correção de erros (VEC), constatou-se que variáveis associadas aos modelos keynesianos (nível de atividade/demanda, crédito e expectativas) apresentaram melhor poder explicativo em nossa variável de interesse. Nas considerações finais, nossos resultados são contrastados com a literatura recente sobre as perspectivas de crescimento da economia brasileira.

PALAVRAS-CHAVE: investimento privado; modelos keynesianos; Brasil; crescimento econômico.

CLASSIFICAÇÃO JEL: E12; E22; O11.

Correspondência para: André M. Cunha

E-mail: andre.cunha@ufrgs.br. 


\title{
MACROECONOMIC DETERMINANTS OF INVESTMENT IN BRAZIL: AN EMPIRICAL ANALYSIS FOR THE PERIOD 1996-2012
}

\begin{abstract}
This paper aims at analysing the macroeconomic determinants of the aggregate private investment in the Brazilian economy from 1996 to 2012. The paper presents the main investment theories, contrasting neoclassical and Keynesian models, reviews the previous empirical literature and provides potentially new evidence on the topic. Our results suggest that the variables usually associated with Keynesian models, such as credit, demand and expectations, have better explained the private investment dynamic in Brazil. Finally, we have also explored relationships between our results and the contemporary debate on Brazil's economic growth performance.
\end{abstract}

KEYWORDS: private investment; Keynesian models; Brazil; economic growth. 


\section{INTRODUÇÃO}

O presente trabalho discute os determinantes do investimento privado na economia brasileira no período 1996-2012. Mais especificamente, busca-se compreender quais variáveis macroeconômicas afetaram os gastos com bens de investimento no segmento de máquinas e equipamentos (FBME) no referido período. Procura-se contribuir com a literatura prévia, expressa em trabalhos como os de Dailami (1987), Studart (1992), Rocha e Teixeira (1996), Melo e Rodrigues Júnior (1998), Reis et al. (1999), Ribeiro e Teixeira (2001), Pereira (2001), Muinhos e Alves (2003), Santos e Pires (2009), dentre outros, e avançar por meio da construção de uma série especial para gastos com máquinas e equipamentos com dados trimestrais, e que será nossa proxy para avaliar o comportamento das inversões. Neste sentido, procuramos avançar nos termos sugeridos por Caballero (1999). Para este autor, a desagregação da série formação bruta de capital é importante, pois permite tratar melhor as irregularidades dos ajustamentos microeconômicos inerentes a cada segmento econômico.

Nossa contribuição está no tratamento empírico desta questão, bem como na busca de contextualizar nossos resultados nos marcos do debate mais geral sobre a dinâmica contemporânea de crescimento da economia brasileira. Para tanto, são utilizadas duas abordagens estatísticas. A primeira delas tem como finalidade decompor as séries utilizadas nos seus componentes não observados. Esse procedimento se faz importante para controlar os choques exógenos ocorridos nas variáveis que serão aproveitadas na segunda abordagem estatística. Esta tem como alvo estabelecer relações entre a FBME e as variáveis selecionadas, que procuram traduzir as principais visões que emergem da literatura teórica e empírica: se os investimentos privados são fundamentalmente determinados pela dinâmica de preços - dos bens de capital e da taxa de juros -, mais associada aos modelos de inspiração neoclássica; ou se por variáveis derivadas dos modeloskeynesianos, tais como expectativas, nível de atividade econômica e oferta de crédito. A estrutura econométrica escolhida para esse segundo exercício estatístico é de um modelo Vetorial de Correção de Erros (VEC).

Além dessa breve introdução, o trabalho se estrutura da seguinte forma: a seção 2 revisa a literatura teórica sobre o tema; a seção 3 apresenta os trabalhos aplicados ao caso do Brasil, os procedimentos adotados e os resultados dos exercícios realizados. Seguem as considerações finais, em que nossas evidências são contrastadas com a literatura recente sobre as perspectivas de crescimento da economia brasileira. 


\section{INVESTIMENTOS PRIVADOS E A DINÂMICA ECONÔMICA: FUNDAMENTOS TEÓRICOS}

Há distinções teóricas importantes no tratamento dos determinantes do investimento, particularmente das inversões privadas, com modelos que enfatizam preços relativos, relações entre componentes da produção e da demanda, fatores psicológicos e institucionais, e assim por diante. Na tradição neoclássica, predominam os modelos em que as decisões de investimento se dão a partir das variações na produtividade marginal do capital e no seu custo de uso, ancoradas em um contexto de pleno emprego onde predomina o poder autorregulador dos mercados capaz de conduzir a economia no sentido de um equilíbrio automático e geral (Caballero, 1997; Kopcke e Brauman, 2001; Romer, 2011; Lim, 2013). Em direta oposição à visão neoclássica há as concepções teóricas que se fundam no princípio da demanda efetiva, em que a acumulação da riqueza privada se dá em um ambiente de incerteza e a existência de pleno emprego e de equilíbrio é apenas um dos resultados possíveis (Davidson, 2011). Há, ainda, modelos baseados no princípio do acelerador (Junankar, 2008), no qual variações no produto geram variações no estoque planejado de capital e, com isso, determinam a demanda por bens de capital (ou o investimento). Combinado com o princípio do multiplicador, tal visão está no centro dos modelos do tipo Harrod-Domar para a explicação dos ciclos econômicos (Taylor, 2004; Medio, 2008).

Dentre os modelos que enfatizam os preços relativos, usualmente associados à literatura neoclássica, predominam três metodologias para a determinação da demanda por investimento: o critério do valor presente; o critério do estoque de capital de equilíbrio e a teoria q-investimento (ou q de Tobin) ${ }^{1}$. Na primeira, as empresas elencam os projetos de investimento tomando como referência o seu valor presente líquido. Este, por sua vez, emerge da subtração dos custos do projeto com seu retorno corrente, isto é, a renda corrente descontada pelo valor da taxa de juros de mercado nos "n" períodos que esta inversão proporcionará retorno. A teoria do estoque de capital de equilíbrio é uma extensão da teoria do valor presente (Jorgenson, 1963). Considera que, nas decisões de investimento, as firmas buscam atingir certo volume ótimo de capital, compatível com o objetivo da maximização do seu valor, observando-se os fluxos de lucros futuros.

A teoria q-investimento foi proposta por Tobin (1969) e utiliza o entendimento neoclássico de investimento em um modelo de equilíbrio geral estruturado sobre as bases da IS-LM. Tobin (1969) busca uma maneira de mensurar as variáveis não observáveis que influenciam a demanda por investimento. Para ele, o melhor sinalizador

Tais abordagens são criticadas "desde dentro", como atesta a teoria das opç̃oes reais (Pindyck, 1991; Hubbard, 1994). 
destas variáveis, em geral expectacionais, estava no mercado financeiro, mais especificamente no preço das ações ${ }^{2}$. Este se forma em condições concorrenciais.

Em equilíbrio, há igualdade entre o valor de mercado da firma (seu preço de demanda) e o custo de reposição de seus ativos (o preço de oferta), de modo que o "q" de Tobin é unitário. Neste caso, não há incentivos para a firma investir. Este só emerge se o "q" for superior à unidade. Formalmente:

$$
\frac{\left[\frac{1}{(1+r)}\right] \cdot\left[P_{t} \cdot y_{k}+P_{t}^{i} \cdot(1-\delta)\right]}{P_{t-1}^{i}}=1=q_{\text {marg }}
$$

O numerador da equação (1) é o valor de mercado da firma no período $t$, descontado para o período $(t-1)$. O primeiro termo, $P_{t} \cdot y_{k}$, representa a ampliação nas vendas, e o segundo, $P_{t}^{i} \cdot(1-\delta)$, o incremento no estoque de capital. Todos os dois no tempo $t$, sendo a soma descontada para o tempo $(t-1)$. Por outro lado, no denominador tem-se o custo de um pequeno aumento no estoque de capital em $(t-1)$. Em outras palavras, o que se tem são os ganhos de um mínimo aumento no imobilizado da empresa dividido pelo seu custo, desde logo, o $q_{\text {marg }}$. O sucesso da teoria q-investimento, entre os economistas de abordagem neoclássica, deve-se ao fato de que, por hipótese, as expectativas de mercado a respeito da lucratividade futura do investimento estão totalmente contempladas na evolução dos preços de suas ações ${ }^{3}$.

Há, também, as tradições pós-keynesiana e estruturalista, que estabelecem importantes contrapontos com os modelos neoclássicos (Mott, 2003; Taylor, 2004; Davidson, 2011). Keynes ${ }^{4}$ (1984[1936]), ao formular suas concepções teóricas, procurou elucidar o porquê da produção e do emprego sofrerem tamanhas flutuações nas economias capitalistas. Nesse sentido, em uma economia sem governo e fechada para trocas externas, renda e emprego dependem, sobremaneira, das demandas por consumo e por investimento. $\mathrm{O}$ consumo é uma função da renda e apresenta certa estabilidade em relação à produção total da economia. Já os dispêndios com o investimento, passíveis de grandes variações com o passar do tempo, são o agregado macroeconômico mais ativo na elucidação da maioria das flutuações do nível de emprego (Minsky, 1975, p. 94).

2 O valor de mercado das ações ajuda a medir a diferença entre o estoque de capital efetivo e o estoque de capital de equilíbrio.

3 Todavia, o investimento agregado não responderá, de forma contínua, apenas pelas trocas nos valores de mercado das empresas (Berndt, 1991, p. 259).

4 A teoria dos determinantes da demanda por investimento formulada por Keynes tem sido interpretada a partir de dois tipos de recortes explicativos. O primeiro, mais convencional e exposto na maioria dos manuais tradicionais de macroeconomia, aproxima-se da forma como a Teoria Neoclássica trata este problema, nos termos expostos anteriormente. A segunda guarda amparo nas escolas pós-keynesiana e estruturalista. 
Em sua leitura pós-keynesiana, a análise determinante do investimento parte da percepção de que há uma relação inversa entre o preço de demanda do ativo $\left(P_{I}^{D}\right)$ e a taxa de juros de mercado. Ao mesmo tempo, três seriam os fatores que podem causar flutuações nos gastos com investimento: (i) as expectativas de rendimento futuros; (ii) a taxa básica de juros esperada, determinada nos mercados de financiamento; e (iii) a relação entre o fator de capitalização da renda esperada sobre os ativos de capital e a taxa de juros para empréstimos monetários, isto é, o fator risco (Minsky, 1975, p. 95-96). Formalmente, temos:

$$
P_{I}^{D}=\frac{Q_{1}}{1+r_{1}}+\frac{Q_{2}}{1+r_{2}}+\ldots \ldots \ldots \ldots . . .+\frac{Q_{n}}{1+r_{n}}
$$

Em (2), $P_{I}^{D}$ é o preço de demanda do investimento; $Q_{1} \ldots . . . Q_{n}$ remete às expectativas de rendimento da inversão; e $r_{1} \ldots . . . . . r_{n}$ é a taxa básica de juros de mercado esperada. As expectativas de renda não são alcançadas partindo da produtividade marginal do capital. Tal componente é endógeno à estrutura cíclica da economia e estaria relacionada com a escassez do capital. Em momentos de aceleração da atividade econômica, há uma tendência de diminuir a ociosidade tanto do capital quanto do trabalho, sendo que, em períodos caracterizados por depressão econômica, o inverso acontece. Além do estoque de capital, tem-se a expectativa de renda como determinante dos rendimentos esperados de um plano de investimento.

$$
\begin{gathered}
Q_{n}=Q_{n}\left(K_{n}, Y_{n}\right) \\
\frac{\partial Q_{n}\left(K_{n}, Y_{n}\right)}{\partial K_{n}}<0
\end{gathered}
$$

A equação (4) oferece uma relação inversa entre $Q_{n}$ e $K_{n}$, e, sabendo que a quantidade de capital relaciona-se de forma positiva com o fluxo de investimento, um aumento neste último agregado leva a uma queda nos retornos esperados. Com base na equação (2), tem-se que um aumento no fluxo de investimento está associado à diminuição nos retornos esperados, onde se mantendo constante a taxa esperada de juros básica de mercado, há queda no preço de demanda do bem de capital. Então, para manter a igualdade válida, sem alterar o preço de demanda do capital, é necessária uma diminuição da taxa de juros. Configura-se, portanto, uma relação inversa entre a demanda por investimento e a expectativa da taxa de juros básica de mercado.

Nota-se aqui uma expressiva influência das expectativas na determinação dos gastos em bens de capital. Com efeito, é importante uma caracterização do papel destas, especificada na incerteza dos retornos esperados. Keynes (1984, p. 171) define "conhecimento incerto", que se fundamenta no estado de expectativa com relação ao futuro. Apesar das incertezas envolvidas no processo da tomada de decisão do investimento, estes gastos acabam por se concretizar, sendo necessário certo nível de informações confiáveis. 
Keynes (1984, p. 172) apresenta basicamente três informações nas quais os agentes econômicos se fundamentam para tomarem suas decisões. A primeira delas é a que supõe, em relação às experiências passadas, que o presente constitui um melhor alicerce para o futuro, isto é, em geral, o processo de formação de expectativa é via adaptação. Outro elemento utilizado pelos empresários na tomada de decisão sobre os dispêndios com investimentos está na crença de que o vigente estado de opinião se baseia em um resumo correto das futuras perspectivas. A última informação relevante para se tomar a decisão de investir está naquilo que Keynes chama de opinião convencional, definida como o comportamento mais usual da maioria dos indivíduos em um determinado momento, a opinião média do mercado.

Se Keynes (1984) deu proeminência ao investimento na elucidação dos movimentos cíclicos da economia, Minsky $(1975,1982)$ avançou na discussão da dinâmica de seu financiamento. As posturas financeiras das empresas se alteram ao longo do ciclo, de modo que se pode transitar de situações de menor fragilidade, caracterizadas como hedge, para outras de crescente exposição às variações endogenamente determinadas de preços-chave, particularmente da taxa de juros. Na medida em que as receitas correntes das empresas não são capazes de cobrir seus gastos com o endividamento gerado por suas próprias decisões passadas de investimento, as mesmas vão migrando para condições especulativas e, finalmente, Ponzi.

Kalecki (1989[1954]), por seu turno, apresenta a sua teoria da demanda por investimento desconsiderando as variações na taxa de juros como suficiente para alavancar a formação bruta de capital fixo. Em uma análise explicitamente dinâmica, este autor sugere que três seriam os principais fatores de determinação dos gastos com investimento: a acumulação interna dos empresários; a taxa de lucro destes e um fator exógeno, ligado às oportunidades de investimento não relacionadas com o princípio da demanda efetiva. Dentro da abordagem estruturalista (Taylor, 2004), trabalha-se a partir dos insights originais de Keynes e Kalecki. Tendo por base este último, a escola estruturalista enfatiza a importância da distribuição funcional da renda. Esta variável e a utilização da capacidade instalada determinam a taxa de lucro, e, com isso, influenciam os gastos com investimento do setor privado.

\section{DETERMINANTES DOS GASTOS COM MÁQUINAS E EQUIPAMENTOS NO PERÍODO 1996-2012}

Esta seção tem como objetivo apresentar os resultados estatísticos para um modelo que busca compreender as variáveis macroeconômicas que determinam os gastos com bens de investimento, exclusivamente máquinas e equipamentos (FBME) para a eco- 
nomia brasileira. Procura-se contribuir com a literatura empírica prévia, que se inspira em modelos neoclássicos e keynesianos. Tais estudos procuram desagregar os componentes privado e público dos investimentos, de modo a analisar os determinantes das inversões oriundas das decisões empresariais. Como o Sistema de Contas Nacionais do IBGE não fornece estimativas desagregadas dos investimentos privados e públicos em bases trimestrais ${ }^{5}$, os trabalhos prévios que buscam tal desagregação usualmente utilizam dados anuais, como em Dailami (1987), Studart (1992), Rocha e Teixeira (1996), Melo e Rodrigues Júnior (1998), Ribeiro e Teixeira (2001). Exceções a tal padrão são trabalhos como os de Reis et al. (1999), Pereira (2001), Muinhos e Alves (2003), e Santos e Pires (2009), que utilizam dados trimestrais ${ }^{6}$.

A literatura empírica ${ }^{7}$ usualmente utiliza as seguintes variáveis como sendo explicações potenciais para o investimento: (i) o nível de atividade da economia, expresso pelo produto interno bruto (PIB) a preços constantes ou pelo grau de utilização da capacidade, o qual se assume como positivamente relacionado com o investimento; (ii) o crédito, dado pelas operações de crédito - especialmente as do BNDES - ou pelo acesso a fontes internacionais de financiamento; (iii) componentes autônomos do gasto agregado, particularmente o investimento público (série anual do IBGE da Formação Bruta de Capital Fixo da administração pública), que poderia induzir investimentos privados, assumindo-se, portanto, uma relação positiva com este, ou deslocálos, com a emergência de uma relação negativa; (iv) o custo do capital, com impactos negativos sobre as decisões empresariais de inversão, e cujas medidas mais comuns são a taxa de juros real e/ou o preço dos bens de capitais, em termos relativos a outros preços ou deflacionado; ; e (v) a incerteza, cuja proxy mais utilizada é a inflação.

5 As restrições impostas pelo modelo VAR/VEC em relação aos graus de liberdade impossibilitam a utilização da série FBME em frequência anual. Entretanto, o anexo III apresenta a boa aproximação obtida para o indicador trimestral construído a partir dos dados anuais da FBCF.

6 Tais trabalhos ou assumem que a formação bruta de capital é proxy suficiente para definir o investimento privado, ou não tratam explicitamente da necessidade de diferenciar o investimento privado do público. O trabalho de Santos e Pires (2009) merece menção especial por construir estimativas da formação bruta de capital privado em bases trimestrais, como resíduo dado investimento total e uma série também trimestral de investimentos públicos.

7 Resultados da literatura empírica internacional estão, dentre outros, em Caballero (1997), Kopcke e Brauman (2001), Romer (2011) e Lim (2013). Este último enfatiza aspectos institucionais, como medidas do ambiente de negócios, além de reforçar a literatura que enfatiza a ligação entre desenvolvimento financeiro (capturado por medidas como relação crédito/PIB ou capitalização dos mercados acionários como proporção do PIB etc.) e crescimento.

8 Muinhos e Alves (2003) assumem que a receita pública é um dos determinantes do investimento público e, por sua vez, Santos e Pires (2009) procuram verificar o efeito da tributação enquanto custo do investimento. 
O presente estudo, que utiliza periodicidade trimestral, considerando os anos completos de 1996 a 2012, trabalha com variáveis convergentes com as literaturas teórica (seção 2) e empírica previamente mencionadas. Tal procedimento facilita o estabelecimento de comparações dos resultados. Como proxy do investimento privado, optou-se por trabalhar com os gastos na aquisição de máquinas e equipamentos $(\mathrm{FBME})^{9}$. Ou seja, busca-se decompor a variável Formação Bruta de Capital Fixo (FBCF) no seu componente FBME. É interessante lembrar que as informações dos investimentos em máquinas e equipamentos fornecidas pelo IBGE são definidas anualmente. Todavia, partindo de uma metodologia que captura o movimento dos gastos com insumos típicos da construção, quantificado também pelo IBGE, foi possível chegar a um indicador da FBME com periodicidade trimestral ${ }^{10}$.

Para as séries econômicas que representam o nível de atividade econômica e que, portanto, se coadunam mais com a tradição keynesiana, em suas múltiplas vertentes, foram escolhidas as que seguem: consumo das famílias (CF); consumo do governo (CG); e exportações de bens e serviços não fatores (EX), originalmente coletadas a preços correntes ${ }^{11}$. Tais séries passaram pelo seguinte conjunto de tratamentos nos dados: conversão a valores constantes a preços de 2011, ajuste sazonal pelo método X-12 Arima e transformação logarítmica. Essas mesmas transformações foram aplicadas à série da FBME.

Já a série do crédito total da economia foi obtida no Banco Central e deflacionada pelo IGP-DI (CRED). Tal série representa a disponibilidade de recursos para financiamento da economia como um todo. Também foi empregada a utilização da capacidade instalada da indústria, que teve como fonte a Fundação Getulio Vargas, com ajuste sazonal e transformação logarítmica (UCI). Essa variável busca identificar o nível de atividade da economia, mas percebe-se, também, que seus movimentos embutem um componente de expectativa. Essa afirmação é confirmada ao se comparar a estatística Z da UCI com essa mesma estatística da série da sondagem industrial geral - índice de confiança da indústria (EXPECTATIVAS), que tem como fonte a FGV. Conforme pode ser observado na Figura 1 , tais séries apresentam um padrão de comportamento muito semelhante, sendo a variável UCI mais volátil do que a variável EXPECTATIVAS. Com isso, emprega-se, neste exercício estatístico, a UCI como um componente que reflete o comportamento do nível de atividade da economia e das expectativas futuras dos empresários.

\footnotetext{
9 Assume-se que tal gasto é eminentemente privado, ou que, se oriundo de decisões de empresas estatais, obedece a determinantes semelhantes.

${ }^{10} \mathrm{O}$ anexo II apresenta a metodologia utilizada para aproximação da série FBME trimestral a partir da série anual da FBCF.

11 A fonte dos dados brutos é o Sistema de Contas Nacionais do Instituto Brasileiro de Geografia e Estatística (SCN/IBGE).
} 
Figura 1 - Estatística Z da UCl e das Expectativas (1996-I até 2012-IV)

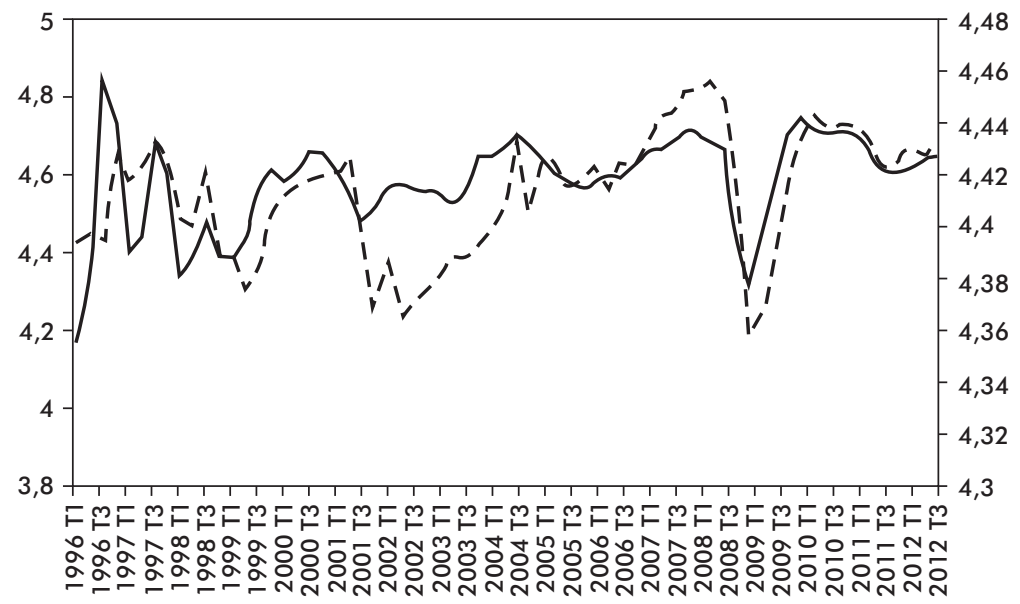

Estatísticas Z EXPECTATIVAS $\quad$ - - - - - Estatística Z UCl

Fonte: Elaboração própria com base em dados da Fundação Getulio Vergas (FGV).

As próximas variáveis procuram se aproximar da noção de custo do capital, ao espírito dos modelos neoclássicos. Todas passaram por ajuste sazonal, como mesmo método já definido anteriormente, e sofreram transformação logarítmica. A primeira série corresponde aos preços de máquinas e equipamentos, qual seja: índice de Preços por Atacado - Oferta Global (IPA-OG) -, produtos industriais - máquinas e equipamentos, variável disponibilizada pela Fundação Getulio Vargas (FGV). Essa série foi deflacionada por dois índices de preços diferentes, o índice geral de preços - demanda interna (IGP-DI) - e o índice de preços ao consumidor amplo (IPCA) (respectivamente, PME/IGP e PME/ IPCA). As outras séries que definem comportamento de preços são as taxas de juros que representam a "policy rate" (SELIC) e o custo básico do crédito de longo prazo, a assim chamada taxa de juros de longo prazo (TJLP), que tiveram como fonte o Banco Central e o Banco Nacional de Desenvolvimento Econômico e Social, respectivamente. Essas duas séries foram deflacionadas pelos índices de preços definidos anteriormente (SELIC/ IPCA, SELIC/IGP, TJLP/IPCA e TJLP/IGP) e pelo IPA-OG (SELIC/IPA e TJLP/IPA).

Definidas as séries de dados utilizadas, parte-se para a decomposição das mesmas em seus componentes não observados. A metodologia estatística escolhida para essa decomposição é a dos modelos Estruturais de Espaço de Estados ${ }^{12}$ (ver Anexo I). Tal método é utilizado para detectar e controlar quebras e outliers. Com isso, as variáveis

\footnotetext{
12 Ver: Harvey e Shephard (1993), Harvey (1989), Commandeur e Koopman (2007) e Hamilton (1994).
} 
que serão utilizadas no modelo VAR/VEC serão aquelas com os choques exógenos controlados no interior da própria série ${ }^{13}$.

Figura 2 - Formação Bruta de Máquinas e Equipamentos em logaritmo e as perturbações padronizadas estimadas para o nível da tendência e irregularidades (1996-I até 2012-IV)
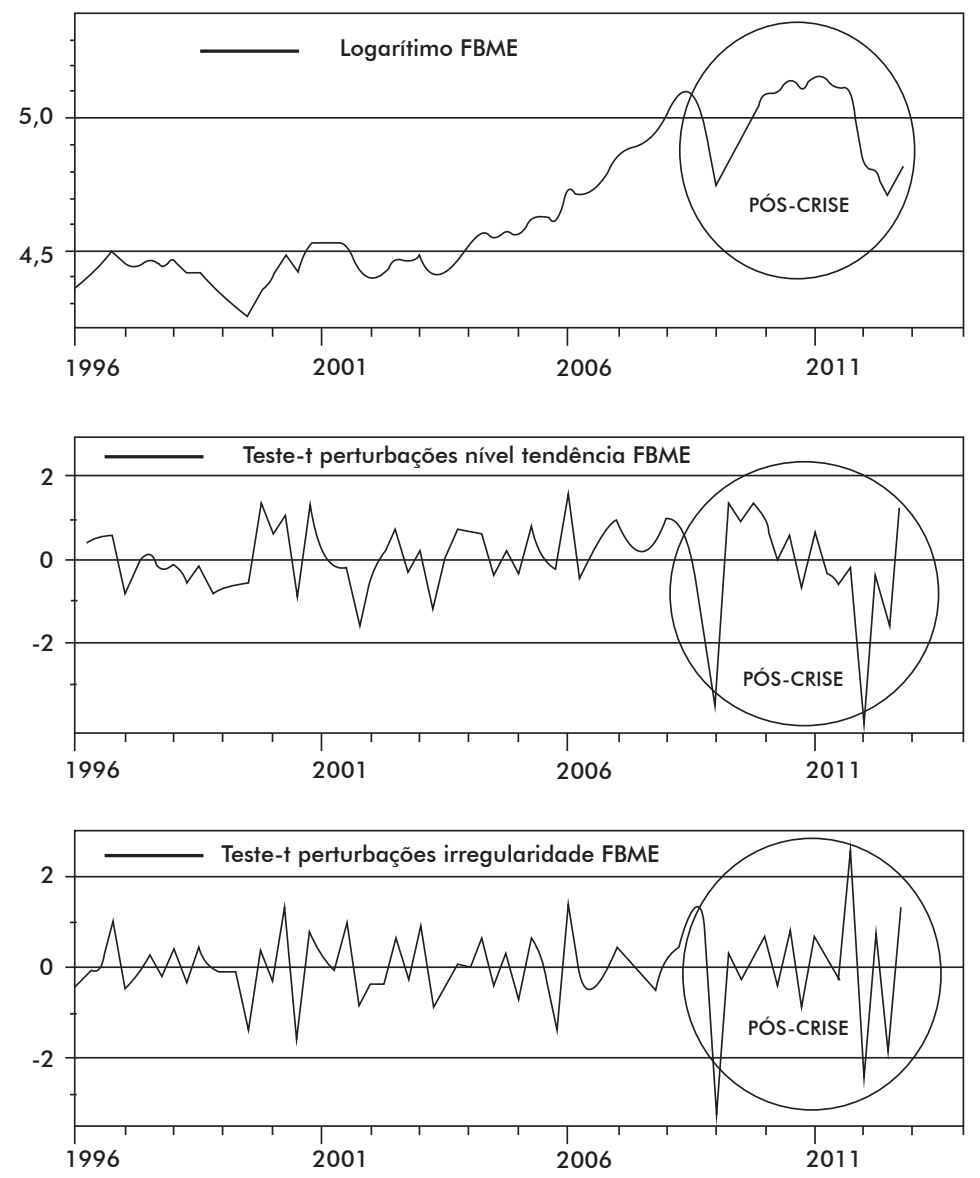

Fonte: Elaboração própria com base em dados do IBGE e estatísticas estimadas a partir do software STAMP 8.

A Figura 2 caracteriza a série da FBME em logaritmo e as estimativas das perturbações padronizadas para o nível da tendência e para as irregularidades. Foram

${ }^{13}$ Segundo Wooldridge (2010, p. 306) é importante ter atenção à presença de outliers nas séries utilizadas em modelos econométricos, pois podem afetar de maneira significativa os resultados finais. Ademais, Hamilton (2009, p. 258-263) e Gujarati (2000, p. 470-471) salientam que a presença de valores extremos pode causar alterações drásticas não somente no valor dos parâmetros estimados, mas, também, no sinal deles. 
detectadas duas quebras de nível da tendência e três outliers ${ }^{14}$, sendo que todos estes pontos são particularizados após a crise subprime (2008-III). Além dessas evidências é possível identificar uma maior volatilidade nas duas séries de resíduos auxiliares estimadas no período pós-crise. Esta alteração de comportamento na FBME após 2008-III confirma a necessidade de estabelecerum controle exógeno para essa variável.

A presença de quebra de nível da tendência se deu nos seguintes trimestres: 2009-I e 2012-I, não por coincidência os trimestres seguintes às evidências da crise do mercado estadunidense (outubro de 2008) e da confirmação dos problemas econômicos na Europa (outubro/novembro de 2011). Já os outliers são estimados para 2009-I, 2011-IV e 2012-I. As estatísticas dos modelos com as intervenções de quebra no nível da tendência e o modelo sem estas intervenções são apresentados na Tabela 1.

Tabela 1 - Estatísticas estimadas para o modelo univariado da FBME com intervenção e sem intervenção (1995-I até 2012-IV)

\begin{tabular}{ccc}
\hline Componentes & Sem intervenção & Com intervenção \\
\hline$\mu_{t}$ & $4,803(0,000)$ & $5,3256(0,000)$ \\
$\beta_{t}$ & $0,0065(0,4519)$ & - \\
NÍVEL 2009-I & - & $-0,2363(0,000)$ \\
NÍVEL 2012-I & - & $0,2855(0,000)$ \\
$\sigma_{\varepsilon}^{2}$ & 0,0000 & \\
$\sigma_{\eta}^{2}$ & & 0,0000293 \\
$\sigma_{\zeta}^{2}$ & 0,00494 & \\
\hline Normalidade, $N$ & 0,0000 & - \\
H(23) & & \\
Box-Ljung, Q(9,7) & Estatísticas resíduos estimados & 0,72934 \\
$R^{2}$ & 20,190 & 1,4028 \\
AIC & 3,7678 & 5,971 \\
BIC & 11,939 & 0,95956 \\
\hline
\end{tabular}

Nota: A estatística entre parênteses representa o p-valor.

Fonte: Elaboração própria com estatísticas estimadas a partir do software STAMP 8.

\footnotetext{
14 As quebras de nível da tendência e os outliers ocorrem nos mesmos trimestres. No entanto, o valor da estatística-t nas quebras de nível de tendência são maiores, apontando que é preferível estabelecer as quebras estruturais vis-à-vis os outliers. Além disso, estimou-se um outliers com uma estatística-t consideravelmente próxima de 2,00 um trimestre antes de uma quebra de nível da tendência (2011-IV). Com isso, esse outlier acaba por perder significância estatística.
} 
Nota-se que o parâmetro referente à declividade da tendência no modelo sem intervenção não alcançou significância estatística, definindo uma estrutura econométrica para a FBME de nível local ${ }^{15}$. Ademais, as estatísticas apontam que os resíduos estimados não são normais e não se rejeita a hipótese da presença de heterocedasticidade e de autocorrelação ${ }^{16}$. O componente $\sigma_{\varepsilon}^{2}$ foi estimado com um valor nulo, reforçando a hipótese de que as intervenções são apenas de quebra de nível da tendência.

Já no modelo com as intervenções, caracteriza-se a significância estatística para as duas variáveis de controle inseridas nessa estrutura econométrica. Com isso, tem-se um expressivo ganho no ajuste do modelo aos dados originais $\left(R^{2}\right.$ e critério de Akaike e Schwarz). Por fim, não se pode rejeitar que os resíduos são homocedásticos $[H(23)]$, não apresentam autocorrelação e são normais. Definidas a metodologia e as estatísticas utilizadas na suavização da FBME, lembra-se de que esse mesmo procedimento foi aplicado nas outras séries utilizadas neste trabalho ${ }^{17}$. Constatou-se que somente a variável UCI exibiu irregularidades no mesmo trimestre da FBME, 2009 I.

Esse comportamento não homogêneo na identificação das intervenções corrobora a necessidade de aplicar um controle nas séries antes de impor o modelo VAR/VEC. Um modelo estatístico estruturado em VAR/VEC especifica uma equação para cada variável do modelo proposto mais uma equação de cointegração ${ }^{18}$. Nesse sentido, como as intervenções são diferentes para cada série, torna-se necessário um conjunto de variáveis dummies, no mínimo igual ao número de séries usadas no modelo sugerido $^{19}$, diminuindo o número de graus de liberdade, o que torna, em alguns casos, inexequível o exercício estatístico.

Além disso, antes de aplicar a metodologia VAR/VEC é importante estabelecer uma pré-seleção nas séries candidatas a comporem a estrutura final do modelo Vetorial de Correção de Erros, uma vez que há 14 variáveis candidatas e mais a variável FBME. Para isso, partiu-se das séries já suavizadas inseridas no modelo das equações (1), (2), (3) e (4) do Anexo I. A variável $y_{t}$ é identificada com a FBME, já na equação (1) se inclui mais um componente, caracterizado pelas variáveis que são candidatas a explicar a FBME. Salienta-se que não é necessária a diferenciação das séries emprega-

\footnotetext{
15 Para maiores detalhes ver Harvey (1989) e Commandeur e Koopman (2007).

${ }^{16}$ Detalhes em Commandeur e Koopman (2007).

${ }^{17}$ Os componentes do modelo estrutural de Espaço de Estado e as intervenções que apresentaram significância estatística estão em tabela no anexo.

18 Para maiores detalhes de um modelo VAR/VEC ver Juselius (2006), Favero (2001) e Bardsen et al. (2005).

19 Como o modelo VAR/VEC apresenta o sistema de equações, no qual as equações são definidas em diferença, somente as quebras de nível serão objetivo de controle com variáveis dummies.
} 
das nos modelos de Espaço de Estado, pois se estimam resíduos auxiliares para cada parâmetro, com sua respectiva variância, estabelecendo um comportamento estocástico para os parâmetros estimados ${ }^{20}$. Com efeito, as variáveis que serão empregadas no modelo VAR/VEC são: FBME, CF, CG, EX, PME/IGP, UCI e CRED ${ }^{21}$.

Optou-se por trabalhar com um modelo com VAR/VEC de quatro defasagens, dados os resultados reportados na Tabela $2^{22}$.

Tabela 2 - Critério de informação de Akaike e Schwarz, teste de autocorrelação residual multiplicador de Lagrange e teste de heterocedasticidade de White

\begin{tabular}{ccccccc}
\hline Ordem & \multicolumn{2}{c}{$\mathbf{2}$} & \multicolumn{2}{c}{3} & \multicolumn{2}{c}{$\mathbf{4}$} \\
\hline & AIC & SBC & AIC & SBC & AIC & SBC \\
\cline { 2 - 7 } & $-41,9581$ & $-37,9773$ & $-41,7542$ & $-36,0872$ & $-41,9923$ & $-34,6103$ \\
\hline \multicolumn{7}{c}{ Teste de heterocedasticidade - White } \\
\hline & Chi-sq & p-valor & Chi-sq & p-valor & Chi-sq & p-valor \\
& 896,07 & 0,0087 & 1297,07 & 0,096 & 1647,70 & 0,3352 \\
\hline Ordem & Estatística LM & p-valor & Estatística LM & p-valor & Estatística LM & p-valor \\
\hline $1^{\text {a }}$ & 42,675 & 0,7259 & 46,726 & 0,5658 & 32,976 & 0,9616 \\
$2^{\text {a }}$ & 51,534 & 0,3749 & 46,749 & 0,5649 & 52,761 & 0,3308 \\
$3^{\text {a }}$ & 35,551 & 0,9248 & 33,342 & 0,9574 & 32,826 & 0,9632 \\
$4^{\text {a }}$ & 68,346 & 0,0352 & 69,361 & 0,0293 & 51,611 & 0,3721 \\
$5^{\text {a }}$ & 37,191 & 0,8910 & 32,870 & 0,9627 & 52,606 & 0,3362 \\
\hline
\end{tabular}

Fonte: Elaboração própria com base em estatísticas estimadas a partir do software STAMP 8.

Com respeito à confirmação estatística de que se trata de um modelo VAR /VEC, a Tabela 3 caracteriza os resultados do teste de cointegração de Johansen. Ao se considerar a estatística de traço, em um nível de significância de 5\%, é possível estabelecer cinco equações cointegradas. Já em um nível de significância de 10\% chega-se a seis

20 Para maiores detalhes ver Commandeur e Koopman (2007), capítulo 9.

${ }^{21}$ Ao se utilizarem os testes de Dickey-Fuller “ampliado" e de Phillips Peron chega-se ao resultado de que todas as variáveis são I(1), excluindo a série do CRED no teste de Phillips Peron (ver tabela em anexo). Não obstante a divergência entre os testes, optou-se por estabelecer que o CRED é I(1). Ademais, não foi necessário aplicar o teste de raiz unitária de Zivot-Andews, uma vez que foram controlados os choques exógenos nas séries utilizadas no modelo.

22 Ao se fixar um nível de significância de $10 \%$, verificou-se que os resíduos estimados estão de acordo com as hipóteses clássicas: ausências de autocorrelação e heterocedasticidade. Ao se comparar o modelo de quatro defasagens e o modelo de três defasagens, as estatísticas de Akaike (AIC) e Schwarz (SBC) apontam um melhor ajuste dos dados ao primeiro modelo. Já ao se confrontarem os modelos de quatro defasagens e de duas defasagens, o AIC identifica que o VAR/VEC com quatro defasagens se constitui no melhor ajuste. Ainda se testou o modelo com cinco defasagens, porém, não foi possível aplicar o teste de heterocedasticidade de White, haja vista o número de parâmetros a serem estimados. Notou-se piora no ajuste desse modelo pelas estatísticas de AIC e SBC. 
equações cointegradas. Por sua vez, a estatística de máximo-autovalor individualiza um total de quatro equações cointegradas, tanto a $5 \%$ quanto a $10 \%$ de significância ${ }^{23}$.

Tabela 3 - Valores estatísticos do teste de cointegração de Johansen

\begin{tabular}{ccccc}
\hline $\begin{array}{c}\text { No de equações } \\
\text { cointegradas }\end{array}$ & $\begin{array}{c}\text { Estatística } \\
\text { Traço }\end{array}$ & p-valor & $\begin{array}{c}\text { Estatística } \\
\text { Máximo-autovalor }\end{array}$ & p-valor \\
\hline Nenhuma & 232,58 & 0,0000 & 84,597 & 0,0000 \\
$\leq 1$ & 147,99 & 0,0000 & 43,648 & 0,0190 \\
$\leq 2$ & 104,34 & 0,0000 & 39,206 & 0,0105 \\
$\leq 3$ & 65,137 & 0,0006 & 33,893 & 0,0068 \\
$\leq 4$ & 31,243 & 0,0338 & 16,883 & 0,1776 \\
$\leq 5$ & 14,361 & 0,0736 & 13,236 & 0,0722 \\
$\leq 6$ & 1,1247 & 0,2889 & 1,1248 & 0,2889 \\
\hline
\end{tabular}

Fonte: Elaboração própria com base em estatísticas estimadas a partir do software STAMP 8.

Para interpretar de forma mais consistente os resultados de um modelo dinâmico singularizado em um VAR/VEC é necessário buscar as relações de causalidade nas séries empregadas neste modelo. A Tabela (4) particulariza o teste de causalidade de Granger $^{24}$. Como o objetivo deste trabalho é explicar os movimentos da FBME, na Tabela (4) são apresentados apenas os testes que se referem a essa variável.

Tabela 4 - Valores estatísticos do teste de causalidade de Granger

\begin{tabular}{|c|c|c|}
\hline Hipótese nula & Estatística-F & p-valor \\
\hline$\triangle \mathrm{FBME}$ não causa $\Delta \mathrm{UCI}$ & 0,6086 & 0,6582 \\
\hline$\Delta \mathrm{UCI}$ não causa $\triangle \mathrm{FBME}$ & 5,9093 & 0,0005 \\
\hline$\triangle \mathrm{FBME}$ não causa $\triangle \mathrm{PME} / \mathrm{IGP}$ & 1,3451 & 0,2652 \\
\hline$\Delta \mathrm{PME} / \mathrm{IGP}$ não causa $\Delta \mathrm{FBME}$ & 2,6602 & 0,0424 \\
\hline$\Delta$ FBME não causa $\Delta \mathrm{EX}$ & 0,3153 & 0,8665 \\
\hline$\Delta \mathrm{EX}$ não causa $\triangle \mathrm{FBME}$ & 1,5264 & 0,2075 \\
\hline$\triangle$ FBME não causa $\triangle \mathrm{CRED}$ & 1,3028 & 0,2807 \\
\hline$\triangle \mathrm{CRED}$ não causa $\triangle \mathrm{FBME}$ & 1,5380 & 0,2043 \\
\hline$\Delta \mathrm{FBME}$ não causa $\Delta \mathrm{CF}$ & 0,7159 & 0,5847 \\
\hline$\Delta \mathrm{CF}$ não causa $\Delta \mathrm{FBME}$ & 2,2598 & 0,0746 \\
\hline$\Delta \mathrm{FBME}$ não causa $\Delta \mathrm{CG}$ & 0,8453 & 0,5027 \\
\hline$\Delta \mathrm{CG}$ não causa $\Delta \mathrm{FBME}$ & 0,2725 & 0,8944 \\
\hline
\end{tabular}

Fonte: Elaboração própria com base em estatísticas estimadas a partir do software STAMP 8.

${ }^{23}$ É importante lembrar que o número máximo de equações cointegradas para o modelo econométrico proposto é de seis. Segundo Dickey, Jansen e Thornton $(2007$, p. 20), à medida que se eleva o número de equações cointegradas, o sistema de equações a ser estimado torna-se mais estável. Ou seja, o sistema econômico estimado é estacionário em um conjunto de possíveis direções. Com efeito, é possível afirmar que o VAR/VEC estimado neste trabalho apresenta um grau elevado de estabilidade. Um dos motivos de se alcançar esta estabilidade está no controle dos choques exógenos sofridos pelas séries utilizadas neste exercício estatístico.

${ }^{24}$ Lembre-se que o teste de causalidade de Granger busca estabelecer uma relação de causa de curto prazo. 
Em um nível de significância de 10\%, é possível perceber que as variações nas variáveis UCI, PME/IGP e CF causam no sentido de Granger as alterações nas inversões em máquinas e equipamentos. Ao mesmo tempo, nota-se a independência entre as modificações da FBME e das séries EX, CG e CRED.

Os resultados reportados sugerem que os gastos em máquinas e equipamentos não são completamente autônomos em nível de atividade da economia. Essa afirmação está sustentada pela causalidade, no sentido de Granger, entre a FBME e as séries CF e UCI. O agregado CF representa, em média, mais de $60 \%$ da demanda agregada da sociedade no período analisado. Dessa forma, uma parte representativa das flutuações nessa demanda é definida pelo desempenho do CF, que causa, no sentido de Granger, as flutuações na FBME. Já a variável UCI é tipicamente um indicador de nível de atividade, que, como já mostrado anteriormente, representa, também, as expectativas futuras do setor privado da economia.

Para os componentes de preço, a relação de causalidade, no sentido de Granger, vai da PME/IGP para a FBME. Ou seja, pelo menos ao se considerar uma defasagem de quatro trimestres as alterações nos PME/IGP não são influenciadas pelos gastos em máquinas e equipamentos. Ou seja, não se pode afirmar estatisticamente que existe endogenia entre a FBME e os PME/IGP. Com base nos resultados do teste de causalidade de Granger parte-se para a análise da função Impulso-Resposta.

Os efeitos da função impulso-resposta foram estimados partindo-se de um impulso generalizado. Segundo Pesaran e Shin (1998), os resultados do teste de impulso-resposta, formatados tendo como base o impulso generalizado, independem de como as equações das variáveis endógenas estão ordenadas no interior do modelo VAR/ VEC. A Figura 3 revela nossos resultados.

É possível perceber que os efeitos dos choques no CF e na UCI sobre a FBME corroboram as constatações do teste de causalidade de Granger. Assim, uma elevação no nível de atividade da economia causa, no sentido de Granger, uma alteração positiva e não transitória na FBME. Vale dizer que choques positivos no nível de atividade da economia elevam de maneira permanente os gastos em máquinas e equipamentos. Salienta-se também que, juntamente a este movimento, pode-se afirmar que uma melhora nas expectativas dos empresários, identificada na variável UCI, aumenta a FBME.

Um choque positivo na variável CRED estabelece como resultado a maior elevação positiva nas inversões em máquinas e equipamentos. Esse efeito aponta para a relevância da capacidade de financiamento da economia na busca por alterações na $\mathrm{FBME}^{25}$.

\footnotetext{
25 Sobre a importância do setor financeiro na economia real, ver Minsky (1975 e 1986). Para uma discussão crítica, teórica e empírica sobre os efeitos da estrutura de financiamento e dos fluxos de caixa das em-
} 
Com respeito aos choques no CG observa-se, também, mudança positiva permanentemente na FBME.

Figura 3 - Função impulso-resposta sobre a variável FBME

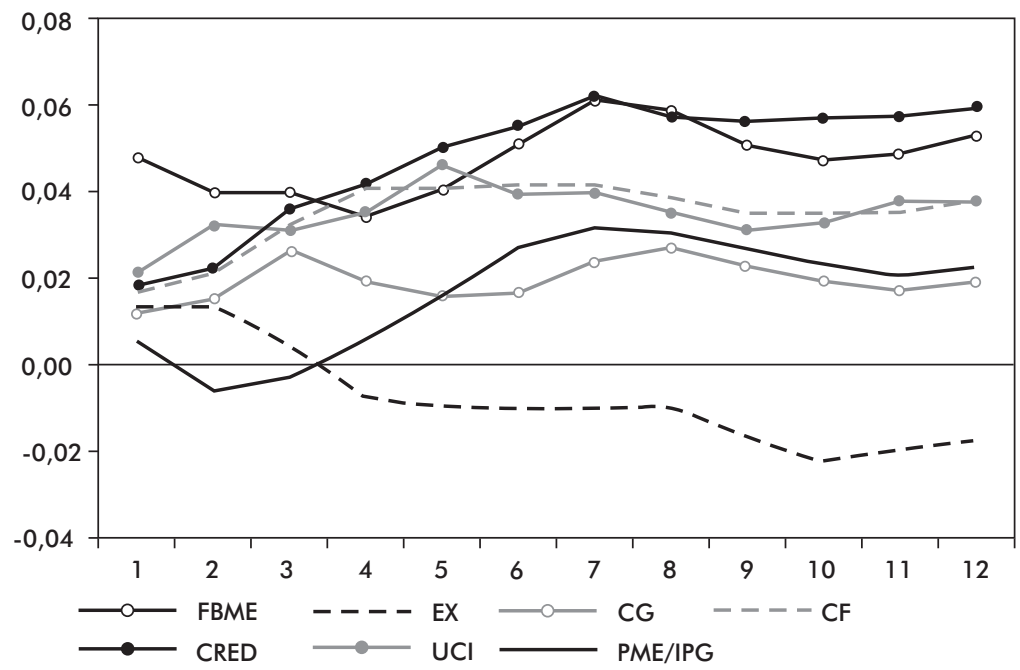

Fonte: Elaboração própria com base em estatísticas estimadas a partir do software STAMP 8.

Não obstante a relação entre FBME e CF, CRED, CG e UCI, dois movimentos acabam por não ser identificados com os padrões da teoria econômica, considerando o sistema de equações construído no modelo VAR/VEC. O primeiro deles está associado à relação entre EX e FBME. Choques em EX afetam positivamente FBME por apenas dois trimestres. Após tal período, há queda nos gastos com máquinas e equipamentos, com um resultado acumulado que se revela. Essa dinâmica pode estar associada à estrutura das exportações brasileiras e sua importância nas alterações do nível de atividade no Brasil. Com respeito à estrutura das vendas externas brasileiras, per-

presas sobre os investimentos, ver Chirinko (1993). Empiricamente, Fazzari, Hubbard e Petersen (1988) analisaram o acesso das empresas ao financiamento externo via mercado de capitais. Os autores mostram que as diferenças existentes entre as empresas, o que abrange o porte, fluxos de caixa e as políticas de distribuição de dividendos, exercem forte influência sobre o acesso e as condições estipuladas pelo mercado ao financiamento de seus investimentos, condições estas que, por vezes, inviabilizam novas inversões e evidenciam a não substituibilidade perfeita entre as fontes de recursos internas (via retenção de lucros) e externas (via mercado de capitais). Para testar tal hipótese no caso brasileiro, seria necessário realizar estudos com microdados, o que transcende aos objetivos propostos no presente estudo. Ainda assim, cabe ressaltar que, para além da importância do acesso ao financiamento externo, o que os nossos resultados corroboram, por meio da efetividade apresentada pela variável crédito, haveria de se observar os efeitos diferenciados sobre as empresas dos diferentes tipos de financiamento externo. 
cebe-se um padrão concentrado em poucos setores e poucas empresas, tal que nos últimos anos depreende-se uma maior relevância dos setores intensivos em recursos naturais. Além disso, nos anos investigados neste trabalho, as EX representaram, em média, $13 \%$ da demanda agregada no Brasil. Nesse sentido, para que os choques positivos nas EX transformem o padrão de atividade econômica brasileira, são necessárias grandes taxas de crescimento. Desde logo, as alterações positivas nas EX têm efeitos limitados sobre a FBME.

O segundo movimento relaciona um impulso positivo nos PME/IGP e o resultado na FBME. Novamente, especifica-se uma relação não observada nas ponderações teóricas. Isto é, alterações positivas nos PME/IGP produzem queda nos gastos com máquinas e equipamentos por apenas dois trimestres, ao passo que se tem uma alteração positiva e permanente na FBME após 12 trimestres. Essa resposta estatística diferente das estruturas teóricas pode estar associada a uma abordagem estática (teórica) vis-à-vis uma abordagem dinâmica (estatística). Ao se caracterizar a relação entre PME/IGP em termos teóricos, pressupõe-se uma relação unidirecional, sem efeito em outras variáveis. Com isso, chega-se à conclusão de que uma elevação nos preços dos bens de capital, em termos reais, causaria uma queda na sua demanda. Todavia, pode-se imaginar que a elevação dos preços dos bens de capital, em termos reais, teria sido gerada por uma mudança de preços relativos, na qual os preços dos bens de consumo crescem menos do que os preços dos bens de capital. Assim, num primeiro momento, é possível esperar uma queda na FBME. No entanto, com o passar do tempo, o consumo da economia poderá se expandir e, como visto anteriormente, a FBME se elevará. Com efeito, estas relações multivariada e dinâmica/temporal não são abordadas pelos padrões teóricos da economia atual. Com isso, a relação entre PME/IGP e FBME não se torna muito evidente no modelo estatístico proposto.

A figura a seguir representa a função impulso-resposta de um impulso na variável FBME com respostas em dois componentes, UCI e CF, o que complementa a análise da Tabela 4. Esta análise permite identificar como se comportariam essas duas variáveis, que se identificam com o nível de atividade da economia após a elevação na FBME. Percebe-se que uma elevação nos gastos com máquinas e equipamentos aumenta tanto a UCI como o CF. Vale dizer que flutuações na FBME também elevam o nível de atividade. 
Figura 4 - Função impulso da FBME resposta sobre as variáveis UCl e CF Resposta na UCI
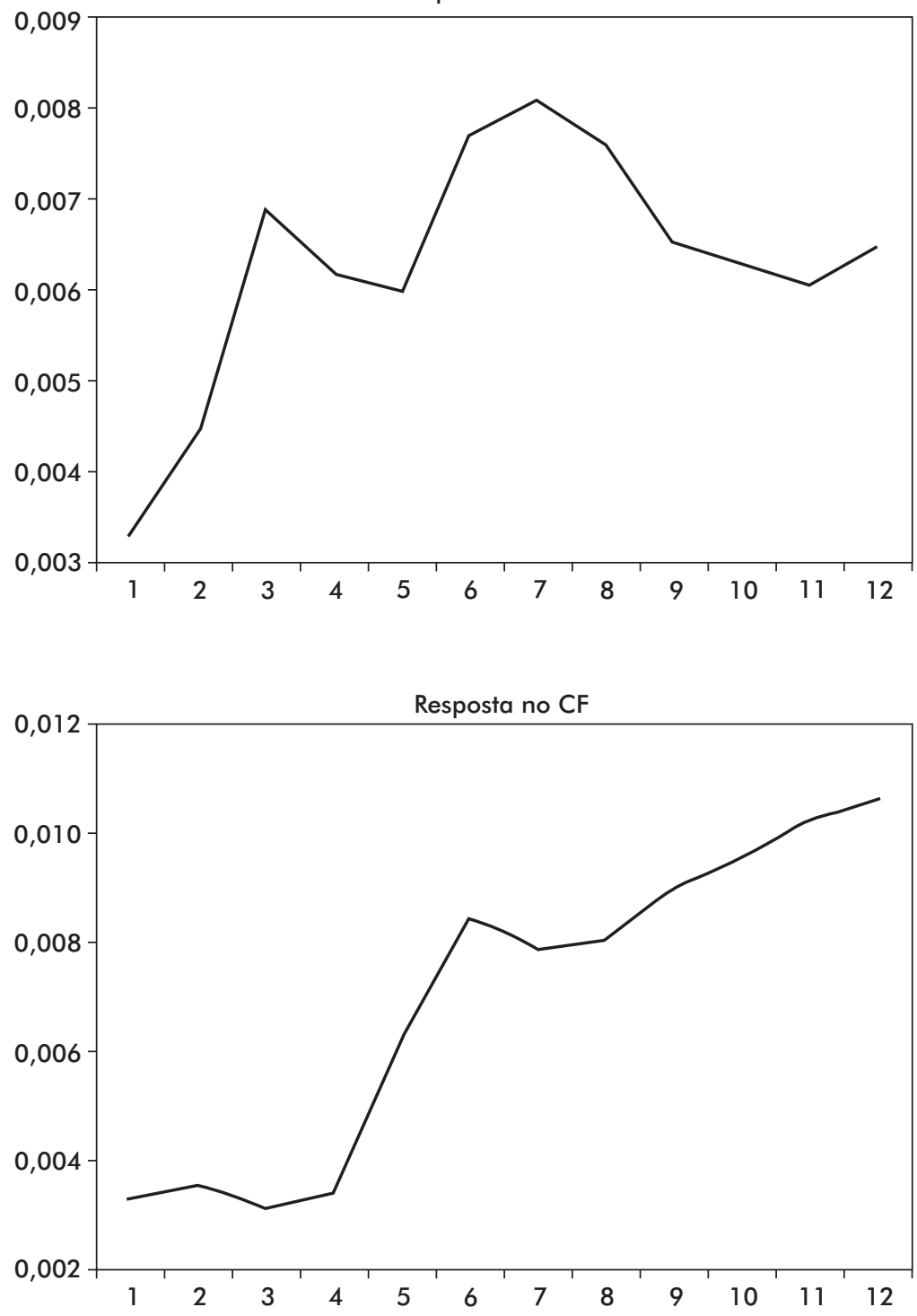

Fonte: Elaboração própria com base em estatísticas estimadas a partir do software STAMP 8.

Em síntese, ao se associarem estes resultados com os anteriores (Tabela 4 e Gráfico 3), indica-se a possibilidade da existência de uma dinâmica consistente com o princípio do multiplicador-acelerador. 


\section{CONSIDERAÇÕES FINAIS: NOSSOS RESULTADOS E O DEBATE SOBRE A PERDA DE DINAMISMO DA ECONOMIA BRASILEIRA}

O presente trabalho apresentou evidências sobre os determinantes macroeconômicos do investimento privado na economia brasileira no período 1996-2012. Procurou-se contribuir com a literatura prévia no tratamento empírico desta questão. Para tanto, foram utilizadas duas abordagens estatísticas: a decomposição das séries utilizadas nos seus componentes não observados e a aplicação de um modelo Vetorial de Correção de Erros (VAR/VEC). A revisão teórica (seção 2) mostrou que há diferentes modelos e, com isso, variáveis potencialmente determinantes das decisões privadas de inversão. Identificou-se que há variáveis de preço, usualmente utilizadas na literatura neoclássica, e variáveis que enfatizam aspectos como nível de atividade, variações em componentes do gasto agregado, financiamento dos gastos e expectativas, mais ao sabor dos modelos de inspiração keynesiana.

Ao se confrontarem tais modelos, verificou-se mais poder explicativo do segundo grupo de variáveis explicativas e, portanto, mais adesão ao padrão sugerido pelos modelos que enfatizam o papel demanda, do financiamento e das expectativas. Assim, os testes de causalidade de Granger indicaram que as variáveis de nível de atividade (CF e UCI) causam a FBME. Observou-se, também, que a UCI representa as expectativas. Com isso, crê-se que existe uma dinâmica do tipo multiplicador-acelerador não explosivo na economia brasileira, em que as variações da FBME são definidas pelo nível de atividade e, ao mesmo tempo, as alterações dessas inversões elevam o nível de atividade. A caracterização do multiplicador-acelerador é uma possibilidade que emerge ao se constatar que um choque positivo no CF ou na UCI eleva os gastos em máquinas e equipamentos. Esse resultado é reforçado pela estatística de causalidade de Granger. Ademais, CRED se caracterizou como a variável mais importante para a elevação da FBME, seguida do nível de atividade (CF e UCI). Enfim, faz-se necessária uma conjuntura econômica de um contínuo nível de atividade elevado e um estoque de crédito suficiente para suprir sua demanda quando se busca alterar o padrão da FBME na economia brasileira. Já as variáveis de preço, particularmente o PME/IGP, condicionam os movimentos da FBME, mas não determinamos investimentos privados nos termos sugeridos pela literatura neoclássica.

Nossos resultados não são novos na literatura, na medida em que outros trabalhos observaram a importância do crédito, de componentes da demanda, do nível de atividade e das expectativas, bem como a menor relevância das variáveis de custo e preços relativos $^{26}$. Ainda assim, procurou-se avançar no tratamento empírico da questão dos

\footnotetext{
${ }^{26}$ Assim, por exemplo, medidas do nível de atividade, do crédito e de expectativas foram os principais determinantes do investimento em Studart (1992), Rocha e Ribeiro (1996), Cruz e Teixeira (1999), Ribeiro e Teixeira (2001), Luporini e Alves (2010). Studart (1992), Rocha e Ribeiro (1996) e Melo e Rodrigues
} 
determinantes do investimento privado na economia brasileira em um período de grande instabilidade. A proposição de uma base trimestral para a aquisição de máquinas e equipamentos, associada ao tratamento das séries pelo método dos modelos de série de tempo estrutural univariado, e a aplicação posterior de um modelo Vetorial de Correção de Erros (VAR/VEC), geraram evidências que potencialmente contribuem para o debate mais geral sobre as perspectivas de crescimento de retomada (ou não) de maior dinamismo na economia brasileira.

Depois de décadas de crescimento acelerado, em meio a intenso processo de industrialização e urbanização, a economia brasileira entrou em um prolongado período de semiestagnação. Esse período se inaugura com a crise da dívida externa, no começo dos anos 1980, e se projeta em anos de forte instabilidade macroeconômica, manifesta, especialmente, na aceleração inflacionária e nos desequilíbrios fiscais e externos. Nem mesmo a superação desses constrangimentos permitiu a retomada do crescimento. De fato, a estabilização monetária inaugurada com o Plano Real, associada às reformas pró-mercado ao espírito do Consenso de Washington, não garantiu a combinação virtuosa de estabilidade macroeconômica com retomada do dinamismo produtivo. $\mathrm{Da}$ mesma forma, o ciclo de expansão do emprego e da renda, com ampliação da inclusão social em meio a um choque externo favorável nos termos de intercâmbio, na primeira década do século XXI, também não se relevou capaz de relançar a economia em uma trajetória sustentada de desenvolvimento.

Os especialistas têm buscado explicar as razões para o colapso do crescimento da economia brasileira. A partir de diferentes perspectivas teóricas, há pelo menos um ponto de convergência: a perda de vigor dos investimentos, que têm se mantido abaixo de $20 \%$ do PIB, e os incrementos modestos da produtividade, são parte essencial do problema. Todavia, divergentes são as explicações para tais fenômenos. Assumindo aqui o risco da simplificação excessiva, sugerimos a existência de pelo menos dois conjuntos de argumentos na literatura. A visão convencional, inspirada nos modelos neoclássicos de crescimento - velhos e novos - e na nova economia institucional, e a visão alternativa, inspirada nas tradições teóricas heterodoxas, especialmente de inspiração estruturalista e keynesiana.

Jr. (1998) enfatizam o papel negativo desempenhado pela instabilidade macroeconômica e/ou pelos investimentos públicos. Já Cruz e Teixeira (1999) encontram uma relação negativa no curto prazo, mas de complementaridade de longo prazo entre os investimentos públicos e privados. Para esses autores, o PIB (como proxy de expectativas) foi o determinante central dos investimentos privados. Já as variáveis de preços relativos ou de custos não foram destacadas como determinantes importantes dos investimentos privados nessa literatura. 
Para os autores alinhados ao que aqui chamamos de "visão convencional", a intervenção estatal durante o período desenvolvimentista, entre os anos 1950 e 1980, e novamente nos anos 2000, gerou: (i) distorções de preços e, em decorrência disso, decisões ineficientes na alocação intertemporal dos recursos, e (ii) um ambiente institucional instável e hostil aos investidores privados (Castelar e Pinheiro, 2006; Bacha e Bonelli, 2005 e 2012; Fishlow e Bacha, 2010; Bonelli e Pinheiro, 2012; Lisboa e Latif, 2013).

As interpretações alternativas criticam o padrão de inserção do Brasil na economia internacional e o viés deflacionista das políticas macroeconômicas. Argumenta-se que, nas últimas três décadas, período que coincide com o aprofundamento da globalização com dominância financeira, o Brasil adotou estratégias equivocadas de inserção externa. A excessiva abertura financeira teria produzido volatilidade excessiva nos preços macroeconômicos fundamentais e crises recorrentes, cujos efeitos se fizeram sentir nos desequilíbrios patrimoniais dos setores privados e público e, com isso, no estreitamento do horizonte temporal nas decisões de reprodução da riqueza. Ademais, as reformas neoliberais teriam diminuído a capacidade estatal em realizar investimentos capazes de sustentar horizontes mais largos de expansão do conjunto da economia. A esses problemas se somariam características mais profundas da sociedade, como a postura rentista e predatória da sua elite (Belluzzo e Almeida, 2002; Arestis e Saad-Filho, 2008; Palma, 2011; Bresser-Pereira, 2009; Carneiro, 2007 e 2012).

Os argumentos da visão convencional convergem para a existência de custos elevados para investir, expressos, por exemplo, na taxa de juros e nos preços dos bens de capital. Já na visão alternativa, a instabilidade macroeconômica gera um padrão de crescimento da renda marcado para taxas baixas e voláteis. Estas determinam posturas defensivas dos agentes privados, que mantêm seus níveis de investimentos em patamares necessários apenas para a proteção de suas posições de mercado, em um ambiente geralmente marcado pela baixa exposição às pressões da concorrência externa. Em síntese: o investimento é baixo porque a demanda corrente (e prospectiva) não se releva suficientemente alta para induzir as decisões privadas de gasto.

Nossos resultados empíricos não permitem corroborar a visão convencional. No período analisado, as variáveis utilizadas para capturar a dinâmica de preços não se revelaram particularmente fortes na determinação dos gastos na aquisição de máquinas e equipamentos, nossa proxy para os investimentos privados. Por outro lado, o comportamento da demanda, do crédito e das expectativas foi mais importante. Nesse sentido, a aceleração na formação bruta de capital nos anos 2000 (ver Gráfico 2), especialmente entre 2004 e 2008, esteve associada a um processo mais amplo de expansão do mercado de consumo, da renda real (e sua melhor distribuição), do emprego e do crédito. A crise de 2007/2008 projetou seus efeitos negativos nos anos seguintes, mesmo que as políticas contracíclicas tenham tentado mitigar seus impactos. 
A partir de 2011, o aparente esgotamento do padrão de crescimento do consumo parece ter afetado negativamente a dinâmica de inversões privadas. Ainda assim, parece ser importante a criação de um ambiente favorável à retomada dos gastos privados em investimento, o que passa, também (mas não somente), pelo reforço dos aspectos virtuosos das políticas que garantiram a ampliação do mercado de consumo. Futuros estudos poderão testar a consistência e a robustez desta hipótese, avançando sobre o esforço prévio da literatura e da nossa contribuição no presente trabalho.

\section{REFERÊNCIAS}

ARESTIS, P.; SAAD-FILHO, A. (Eds.) Political Economy of Brazil: recent economic performance. Basingstoke: Palgrave Macmillan, 2008.

BACHA, E. L.; BONELLI, R. Uma interpretação das causas da desaceleração econômica do Brasil. Revista de EconomiaPolítica, v. 25, n. 3, jul./set. 2005.

BACHA, E.; BONELLI, R. Accounting for the rise and fall of Brazil's post-WW-II growth. Texto para Discussão, Rio de Janeiro, IEPE/CdG, n. 25, 2012. Disponível em: <http://www.iepecdg.com/>. Acesso em: 15/03/2013.

BARDSEN, G. ET AL. The econometrics of macroeconomic modeling. Oxford: Oxford University Press, 2005.

BELLUZZO, L. G. M.; ALMEIDA, S. G. Depois da queda: a economia brasileira da crise da dívida aos impasses do Real. Rio de Janeiro: Civilização Brasileira, 2002.

BERNDT, E. R. The practice of econometrics. Cambridge: Addison-Wesley Publishing Company, 1991.

BONELLI, R.; PINHEIRO, A. C. Brazil's new development model: accomplishments, threats, and policy lessons. Texto para Discussão, IBRE, dez. 2012.

BONELLI, R.; FONTES, J. Desafios brasileiros no longo prazo. Rio de Janeiro: Instituto de Estudos de Política Econômica - Casa das Garças, 2013.

BRESSER-PEREIRA, L. C. Globalization and competition: why some emergent countries succeed while others fall behind. Cambridge: Cambridge University Press, 2009.

CABALLERO, R. J. Aggregate investment. NBER Working Paper, n. 6264, nov. 1997.

CARNEIRO, R. Dinâmica de crescimento da economia brasileira: uma visão de longo prazo. Texto Para Discussão, IE/Unicamp, n. 130, 2007.

CARNEIRO, R. M. Velhos e novos desenvolvimentismos. Economia e Sociedade, Campinas, v. 21, Número Especial, p. 749-778, dez. 2012.

CASTELAR, A. C.; GIAMBIAGI, F. Rompendo o marasmo: a retomada do desenvolvimento no Brasil. Rio de Janeiro: Elsevier, 2006.

CHIRINKO, R. S. Business fixed investment spending: modeling strategies, empirical results, and policy implications. Journal of Economic Literature, v. 31, n. 4, p. 1875-1911, 1993. 
COMMANDEUR, J. J. F.; KOOPMAN, S. J. An introduction to state space time series analysis. Oxford: Oxford University Press, 2007.

CRUZ, B. O.; TEIXEIRA, J. R. The impact of public investment on private investment in Brazil, 1947-1990. Cepal Review, v. 67, p.75-84, abr. 1999.

DAILAMI, M. Expectations, stock market volatility, and private investment behavior: theory and empirical evidence for Brazil. Washington, D.C.: World Bank, Country Economics Department, 1987.

DAVIDSON, P. Post Keynesian macroeconomic theory: a foundation for successful economic policies for the twenty-first century. 2 ed. London: Edward Elgar Pub., 2011.

DICKEY, D.A; JANSEN, D. W; THORNTON, D. L. "A primer on cointegration with an application to money and income". In: RAO, B. B. Cointegration for the applied economist. 2 ed. New York: Palgrave Macmillan, 2007.

FAVERO, C. A. Applied macroeconometrics. Oxford: Oxford University Press, 2001.

FAZZARI, S.; HUBBART, R.; PETERSEN, B. Financing constraints and corporate investment. Brookings Papers on Economic Activity, 1988.

FISHLOW, A.; BACHA, E. "Recent commodity price boom and Latin American growth: more than new bottles for an old wine?" In: OCAMPO, J. A.; ROS, J. (Eds.) Handbook of Latin American Economics. Oxford: Oxford University Press, 2010, p. 394-410.

GUJARATI, D. N. Econometria básica. 3 ed. São Paulo: Pearson Education, 2000.

HAMILTON, J. D. Time series analysis. Princeton, NJ: Princeton University Press, 1994.

HAMILTON, L.C. Statistics with Stata: updated for version 10.7 ed. Canada: Cengage Learning. 2009.

HARVEY, A. C. Forecasting, Structural Time Series Models and the Kalman Filter. Cambridge: Cambridge University Press, 1989.

HARVEY, A. C.; KOOPMAN, S. J. Diagnostic checking of unobserved-components time series models. Journal of Business \& Economic Statistics, v. 10, n. 4, 1992.

HARVEY, A. C.; SHEPHARD, N. "Structural time series models”. In: MADDALA, G. S.; RAO, C. R.; VINOD, H. D. Handbook of Statistics. Vol. 11. Amsterdam: North-Holland, 1993.

JORGENSON, D. W. Capital theory and investment behavior. American Economic Review, v. 53, n. 2, May, 1963.

JUNANKAR, P. N. “Acceleration principle”. In: DURLAUF, S. N.; BLUME, L. E. (Ed.) The New Palgrave Dictionary of Economics. 2 ed. New York: Palgrave Macmillan, 2008.

JUSELIUS, K. The Cointegrated VAR Model: methodology and applications. Oxford: Oxford University Press, 2006.

KALECKI, M. Theory of economic dynamics: an essay on cyclical and long-run changes in capitalist economy. 2 ed. Augustus M Kelley Pubs., 1989 (original, 1954).

KEYNES, J. M. “A teoria geral do emprego". In: SZMRECSÁNYI, T. (Org.) Coleção Grandes Cientistas Sociais. 2 ed. São Paulo: Editora Ática, 1984 (original, The General Theory of Employment, Interest and Money, 1936.) 
KOPCKE, R. W.; BRAUMAN, R. S. The performance of traditional macroeconomic models of businesses' investment spending. New England Economic Review, n. 2, p. 30-39, 2001.

LIM, J. J. Institutional and structural determinants of investment worldwide. Policy Research Working Paper, The World Bank, n. 6591, Sept. 2013.

LUPORINI, V.; ALVES, J. Investimento privado: uma análise empírica para o Brasil. Economia e Sociedade, Campinas, v. 19, n. 3 (40), p. 449-475, dez. 2010.

MEDIO, A. "Multiplier-accelerator interaction”. In: DURLAUF, S. N.; BLUME, L. E. (Eds.) The New Palgrave Dictionary of Economics. 2 ed. New York: Palgrave Macmillan, 2008.

MELO, G. M., RODRIGUES JR., W. Determinantes do investimento privado no Brasil: 19701995. Texto para Discussão, IPEA, n. 605, nov. 1998.

MINSKY, H. P. John Maynard Keynes. New York: Columbia University Press, 1975.

MINSKY, H. P. Stabilizing an Unstable Economy. New Heaven: Yale University Press, 1986

MOTT, T. “Investment”. In: KING, J. E. (Ed.) The Elgar Companion on Post-Keynesian Economics. London: Edward Elgar, 2003.

PESARAN, M. H; SHIN, Y. Generalized impulse response analysis in linear multivariate models. Economics Letters, v. 58, p. 17-29, 1998.

REIS, E. ET AL. Model for projections and simulations of the Brazilian Economy. Texto para Discussão, IPEA, n. 619, 1999.

RIBEIRO, M. B.; TEIXEIRA, J. R. An econometric analysis of private-sector investment in Brazil. Cepal Review, n. 74, p. 153-166, Aug. 2001.

ROCHA, C.; TEIXEIRA, J. Complementaridade versus substituição entre investimento público e privado na economia brasileira: 1965-90. Revista Brasileira de Economia, v. 50, n. 3, p. 378-384, jul./set. 1996.

ROMER, D. Advanced macroeconomics. 4 ed. McGraw-Hill Series Economics, 2011.

SANTOS, C. H.; PIRES, M. C. C. Qual a sensibilidade dos investimentos privados a aumentos na carga tributária brasileira? Uma investigação econométrica. Revista de Economia Política, v. 29, n. 3 (115), p. 213-231, jul./set. 2009.

STUDART, G. Investimento público e formação de capital do setor privado no Brasil: análise empírica da relação de curto e de longo prazos durante o período 1972-1989. Dissertação de Mestrado, Departamento de Economia, Pontifícia Universidade Católica do Rio de Janeiro, Rio de Janeiro, 1992.

TAYLOR, L. Reconstructing macroeconomics: structuralist proposals and critiques of the mainstream. Boston, MA: Harvard University Press, 2004.

TOBIN, J. A. General equilibrium approach to monetary theory. Journal of Money, Credit and Banking, v. 1, n. 1, Feb. 1969.

WOOLDRIDGE, J. M. Econometric analysis of cross section and panel data. 2 ed. Cambridge: The MIT Press, 2010. 


\section{ANEXO I}

\section{MODELO ESTRUTURAL UNIVARIADO}

Os modelos de série de tempo estrutural univariado proposto são formulados da seguinte maneira:

$$
y_{t}=\mu_{t}+\gamma_{t}+\psi_{t}+\varepsilon_{t}
$$

Os componentes não observados são demarcados pela tendência $\left(\mu_{t}\right)$, a sazonalidade $\left(\gamma_{t}\right)$, um componente cíclico $\left(\psi_{t}\right)$ e as irregularidades $\left(\varepsilon_{t}\right)$. Todos os quatro componentes são estocásticos e suas distribuições são mutuamente não correlacionadas. Ou seja, em modelos Estruturais de Espaço de Estado é permitido que os parâmetros estimados não sejam fixos ao longo do tempo. Com isso, ao se observar os movimentos das perturbações desses parâmetros é possível estabelecer os choques exógenos em cada componente não observado da série estudada. Desde logo, para todas as séries analisadas parte-se, primeiramente, de um modelo chamado de tendência local, definido como segue:

$$
\mu_{t}=\mu_{t-1}+\varepsilon_{t} \varepsilon_{t} \sim N I D\left(0, \sigma_{\varepsilon}^{2}\right)
$$

Inserindo um termo estocástico na expressão, tem-se

$$
\begin{gathered}
\mu_{t}=\mu_{t-1}+\beta_{t-1}+\eta_{t}, \quad \eta_{t} \sim N I D\left(0, \sigma_{\eta}^{2}\right) \\
\beta_{t}=\beta_{t-1}+\zeta_{t}, \quad \zeta_{t} \sim \operatorname{NID}\left(0, \sigma_{\zeta}^{2}\right)
\end{gathered}
$$

O componente $\beta_{t}$ representa a declividade da tendência estimada, já os componentes $\eta_{t}$ e $\zeta_{t}$ são os resíduos auxiliares do nível $\left(\mu_{t}\right)$ e da declividade da tendência estocástica, respectivamente. Ademais, define-se que estes componentes são reciprocamente não correlacionados e seguem uma estrutura de ruído branco com média zero e variâncias $\sigma_{\eta}^{2}$ e $\sigma_{\zeta}^{2}$. Nessa especificação permite-se que o nível e a declividade da tendência se alterem ao longo do tempo, de acordo com as trajetórias de $\eta_{t} \mathrm{e} \zeta_{t}$.

O modelo proposto não incluiu os componentes sazonal e cíclico. A não inclusão do primeiro componente foi estabelecida porque a série já se encontra com ajuste sazonal. Já o padrão cíclico não foi imposto pelo número de anos que o estudo aborda, insuficiente para caracterizar ciclos econômicos. Nesse sentido, a estratégia é partir de uma especificação estatística mais geral e de acordo com o comportamento das séries selecionadas para chegar-se a uma estrutura mais particularizada, considerando, também, os choques exógenos. 


\section{ANEXO II \\ METODOLOGIA DE CONSTRUÇÃO DA SÉRIE FBME COM PERIODICIDADE TRIMESTRAL}

Para a estimação da série FBME, foram utilizadas as séries FBCF, com temporalidade trimestral e anual, FBME e Formação Bruta Construção Civil (FBCC) com periodicidade anual, e o índice de produção de insumos típicos da construção civil (ICC), com periodicidades mensal e trimestral, esta estimada por média, utilizada como proxy para a taxa de crescimento da FBCC. O primeiro passo é estimar a variação da participação da FBCC sobre a FBCF da seguinte forma:

$$
\Delta(F B C C / F B C F)=\left[\frac{I C C_{t}}{I C C_{t-1}}\right]-\left[\frac{F B C F_{t}}{F B C F_{t-1}}\right]
$$

$\operatorname{Em}(1)$

$\triangle(F B C C / F B C F)=$ diferença da taxa de crescimento da $F B C C$ em relação à $F B C F$, com periodicidade trimestral;

$\mathrm{ICC}_{t} / \mathrm{ICC}_{t-1}=$ taxa de crescimento do índice de produção de ICC, com periodicidade trimestral; e

$F B C F_{t} / \mathrm{FBCF}_{t-1}=$ taxa de crescimento da $F B C F$, com periodicidade trimestral.

Assim, dado que a $F B C F$ é formada significativamente pela $F B M E$ e $F B C C$, uma queda na participação da $F B C C$ na $F B C F$ representa uma elevação na participação da FBME no fluxo de investimento total da economia. Assim, podemos encontrar a participação relativa trimestral da $F B C C$ na $F B C F$ a partir da seguinte expressão:

$$
\left[\frac{F B C C}{F B C F}\right]_{\text {TRIMESTRAL }}=[1+\Delta(F B C C / F B C F)] \cdot\left[\frac{F B C C_{\$}}{F B C F_{\$}}\right]_{\text {ANUAL }}
$$

$\operatorname{Em}(2)$

$$
\begin{aligned}
& {\left[\frac{F B C C}{F B C F}\right]_{\text {TRIMESTRAL }}=\text { participação percentual da } F B C C \text { na } F B C F \text { com periodici- }} \\
& \text { dade trimestral; e } \\
& {\left[\frac{F B C C_{\$}}{F B C F_{\$}}\right]_{A N U A L}=\text { participação da } F B C C \text { na } F B C F \text { com periodicidade anual. }}
\end{aligned}
$$

A partir desta expressão, chega-se ao resultado de que o valor médio da participação da $F B C C$ na $F B C F$, com periodicidade trimestral, é exatamente igual ao seu valor anual, isto é:

$$
E\left(\left[\frac{F B C C}{F B C F}\right]_{\text {TRIMESTRAL }}\right)=\left[\frac{F B C C_{\$}}{F B C F_{\$}}\right]_{\text {ANUAL }}
$$


Identificando a relação entre $F B C C$ e a $F B C F$ trimestral, por resíduo encontra-se a relação entre a FBME e a FBCF. Com efeito, chega-se a uma boa representação dos movimentos das demandas por máquinas e equipamentos e construção civil com periodicidade trimestral. 


\section{ANEXO III}

Gráfico Alll.1 - FBME com periodicidade média anual, trimestral e tendência do valor trimestral - R\$ milhões a preços constantes de 2011

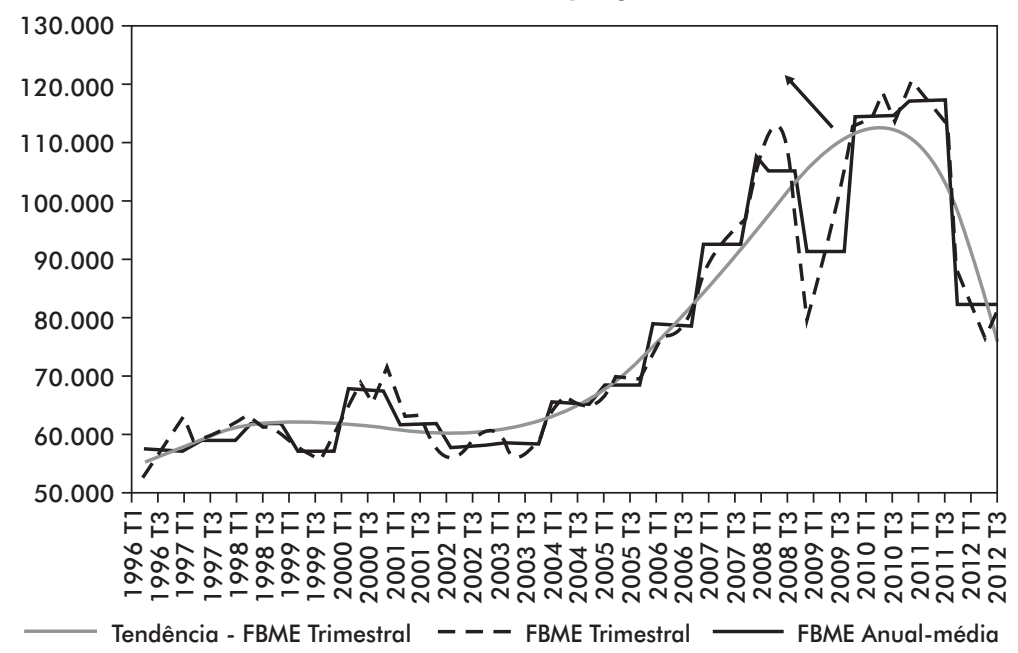

Fonte: Elaboração própria com base em dados de Instituto Brasileiro de Geografia e Estatísticas (IBGE). 


\section{ANEXO IV}

Tabela AIV.1 - Componentes e intervenções estimadas no modelo univariado para as séries selecionadas

\begin{tabular}{|c|c|c|}
\hline SÉRIE & COMPONENTE & INTERVENÇÕES \\
\hline $\mathrm{CF}$ & $\begin{array}{l}\text { NívelEstocástico } \\
\text { DeclividadeEstocástica }\end{array}$ & $\begin{array}{l}\text { Irregularidade: } 1996 \text { IV } \\
\text { Nível: } 2001 \text { III }\end{array}$ \\
\hline CG & $\begin{array}{l}\text { NívelEstocástico } \\
\text { DeclividadeEstocástica }\end{array}$ & $\begin{array}{l}\text { Irregularidade: } 1996 \text { IV } \\
\text { Nível: } 1997 \text { I }\end{array}$ \\
\hline $\mathrm{EX}$ & NívelEstocástico & Nível: 1999 IV; 2002 III \\
\hline CRED & $\begin{array}{c}\text { NívelEstocástico } \\
\text { DeclividadeEstocástica }\end{array}$ & Nível: 1997 IV; 2001 II; 2002 IV \\
\hline PME/IGP & $\begin{array}{c}\text { NívelEstocástico } \\
\text { DeclividadeEstocástica }\end{array}$ & --- \\
\hline PME/IPCA & $\begin{array}{l}\text { NívelEstocástico } \\
\text { DeclividadeEstocástica }\end{array}$ & $\begin{array}{l}\text { Irregularidade: } 1998 \text { IV; } 1999 \text { II } \\
\text { Nível: } 2004 \text { II }\end{array}$ \\
\hline SELIC/IGP & NívelEstocástico & $\begin{array}{l}\text { Irregularidade: } 1999 \text { I; } 2002 \text { IV; } 2008 \text { II } \\
\text { Nível: } 1999 \text { III; } 2003 \text { II }\end{array}$ \\
\hline SELIC/IPA & NívelEstocástico & $\begin{array}{l}\text { Irregularidade: } 1999 \text { II; } 2002 \text { IV } \\
\text { Nível: } 1999 \text { I; } 2002 \text { III; } 2004 \text { I }\end{array}$ \\
\hline SELIC/IPCA & NívelEstocástico & $\begin{array}{c}\text { Irregularidade: } 1999 \text { IV; } 2000 \text { III; } 2002 \text { IV } \\
\text { Nível: } 2003 \text { II }\end{array}$ \\
\hline TJLP/IGP & NívelEstocástico & $\begin{array}{c}\text { Irregularidade: } 1999 \text { I; } 2002 \text { IV; } 2008 \text { II } \\
\text { Nível: } 2003 \text { II }\end{array}$ \\
\hline TJLP/IPA & NívelEstocástico & $\begin{array}{c}\text { Irregularidade: } 1999 \text { I; } 2002 \text { III; } 2002 \text { IV; } 2003 \text { I } \\
\text { Nível: } 2004 \text { I }\end{array}$ \\
\hline TJLP/IPCA & NívelEstocástico & $\begin{array}{l}\text { Irregularidade: } 2000 \text { III } \\
\text { Nível: } 2003 \text { II }\end{array}$ \\
\hline UCI & NívelEstocástico & $\begin{array}{l}\text { Irregularidade: } 1998 \text { III; } 2004 \text { III } \\
\text { Nível: } 1996 \text { IV; } 2001 \text { III; } 2008 \text { IV; } 2009 \text { I }\end{array}$ \\
\hline
\end{tabular}

Fonte: Elaboração própria com base em estatísticas estimadas a partir do software STAMP 8. 
ANEXO $V$

Tabela AV.1 - Estatísticas estimadas para a relação entre FBME e as séries selecionadas

\begin{tabular}{cccc}
\hline SÉRIE & INTERVENÇÕES & PARÂMETRO ESTIMADO & P-VALOR \\
\hline CF & Irregularidade: 2000 III; 2012 III & 1,939 & 0,000 \\
CG & Nível: 2001 IV & 1,727 & 0,004 \\
EX & - & 0,378 & 0,049 \\
CRED & - & 0,736 & 0,001 \\
PME/IGP & Nível: 2008 IV & $-0,885$ & 0,037 \\
PME/IPCA & Irregularidade: 2012 III & $-0,684$ & 0,168 \\
SELIC/IGP & - & $-0,052$ & 0,798 \\
SELIC/IPA & - & $-0,254$ & 0,419 \\
SELIC/IPCA & - & $-0,346$ & 0,113 \\
TJLP/IGP & - & $-0,015$ & 0,947 \\
TJLP/IPA & - & $-0,029$ & 0,892 \\
TJLP/IPCA & - & $-0,253$ & 0,419 \\
UCI & - & 2,647 & 0,000 \\
\hline
\end{tabular}

Fonte: Elaboração própria com base em estatísticas estimadas a partir do software STAMP 8. 
ANEXO VI

Tabela AVI.1 - Estatísticas dos testes de raiz unitária de Dickey-Fuller "ampliado" e Phillips-Peron

\begin{tabular}{|c|c|c|c|c|c|c|}
\hline \multicolumn{4}{|c|}{ Dickey-Fuller "ampliado" } & \multicolumn{3}{|c|}{ Phillips-Peron } \\
\hline $\begin{array}{l}\text { Série de } \\
\text { Dados }\end{array}$ & Estatística t & vC & $\begin{array}{c}\text { Grau de } \\
\text { Integração }\end{array}$ & Estatística t & VC & $\begin{array}{c}\text { Grau de } \\
\text { Integração }\end{array}$ \\
\hline $\operatorname{FBME}(0 / 0)$ & 0,1410 & $\begin{array}{r}5 \%=-2,905 \\
10 \%=-2,590\end{array}$ & $\mathrm{I}(1)$ & 0,0727 & $\begin{aligned} 5 \% & =-2,905 \\
10 \% & =-2,590\end{aligned}$ & $\mathrm{I}(1)$ \\
\hline $\mathrm{CF}(0 / 0)$ & 1,402 & $\begin{aligned} 5 \% & =-2,905 \\
10 \% & =-2,590\end{aligned}$ & $\mathrm{I}(1)$ & 1,1180 & $\begin{aligned} 5 \% & =-2,905 \\
10 \% & =-2,590\end{aligned}$ & $\mathrm{I}(1)$ \\
\hline CG $(1 / 0)$ & 0,3431 & $\begin{aligned} 5 \% & =-2,906 \\
10 \% & =-2,591\end{aligned}$ & $\mathrm{I}(1)$ & 0,1481 & $\begin{aligned} 5 \% & =-2,905 \\
10 \% & =-2,590\end{aligned}$ & $\mathrm{I}(1)$ \\
\hline $\mathrm{EX}(0 / 0)$ & $-0,8063$ & $\begin{aligned} 5 \% & =-2,905 \\
10 \% & =-2,590\end{aligned}$ & $\mathrm{I}(1)$ & $-0,8304$ & $\begin{aligned} 5 \% & =-2,905 \\
10 \% & =-2,590\end{aligned}$ & $\mathrm{I}(1)$ \\
\hline UCI $(1 / 0)$ & 0,3093 & $\begin{aligned} 5 \% & =-2,905 \\
10 \% & =-2,590\end{aligned}$ & $\mathrm{I}(1)$ & 0,0340 & $\begin{aligned} 5 \% & =-2,905 \\
10 \% & =-2,590\end{aligned}$ & $\mathrm{I}(1)$ \\
\hline $\operatorname{CRED}(2 / 0)$ & 1,1739 & $\begin{aligned} 5 \% & =-2,907 \\
10 \% & =-2,591\end{aligned}$ & $\mathrm{I}(1)$ & 1,8314 & $\begin{aligned} 5 \% & =-2,905 \\
10 \% & =-2,590\end{aligned}$ & $\mathrm{I}(2)$ \\
\hline PME/IGP(1/0) & $-0,4085$ & $\begin{aligned} 5 \% & =-2,905 \\
10 \% & =-2,590\end{aligned}$ & $\mathrm{I}(1)$ & $-0,6115$ & $\begin{aligned} 5 \% & =-2,905 \\
10 \% & =-2,590\end{aligned}$ & $\mathrm{I}(1)$ \\
\hline
\end{tabular}

Nota: Os números apresentados ao lado da abreviatura das séries de dados indicam a quantidade de defasagens utilizada na caracterização das séries, considerando, respectivamente, o teste ADF e PP.

Fonte: Elaboração própria com base em estatísticas calculadas pelos programas Eviews 8.0. 